\title{
Natural Hazards and Tourism: New Findings on the European Alps
}

Author(s): Christian Nöthiger and Hans Elsasser

Source: Mountain Research and Development, 24(1):24-27.

Published By: International Mountain Society

DOI: http://dx.doi.org/10.1659/0276-4741(2004)024[0024:NHATNF]2.0.CO;2

URL: http://www.bioone.org/doi/full/10.1659/0276-4741\%282004\%29024\%5B0024\%3ANHATNF

$\% 5 \mathrm{D} 2.0 . \mathrm{CO} \% 3 \mathrm{~B} 2$

BioOne (www.bioone.org) is a nonprofit, online aggregation of core research in the biological, ecological, and environmental sciences. BioOne provides a sustainable online platform for over 170 journals and books published by nonprofit societies, associations, museums, institutions, and presses.

Your use of this PDF, the BioOne Web site, and all posted and associated content indicates your acceptance of BioOne's Terms of Use, available at www.bioone.org/page/terms_of_use.

Usage of BioOne content is strictly limited to personal, educational, and non-commercial use. Commercial inquiries or rights and permissions requests should be directed to the individual publisher as copyright holder. 
Christian Nöthiger

Hans Elsasser

\section{Natural Hazards and Tourism: New Findings on the European Alps}

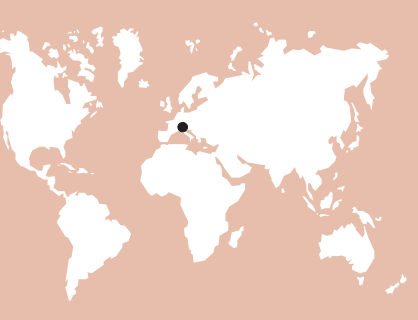

The tourist industry in the European Alps has always been greatly threatened by natural disasters. As far as tourism is concerned, the so-called "indirect" effects of these disasters have proven to be more important than the direct damages. The former consist mainly of loss of earnings, which can result for example from the closure of access roads or the decommissioning of cable cars and ski lifts. In fact, it is the combination of a drop in the number of overnight stays with the absence of day trippers over several days which makes the outcome of a natural disaster an extraordinary event for the tourist industry. As long as natural disasters remain relatively rare occurrences, tourist resorts in the Alps can generally cope with them. Should the frequency of these events increase substantially as a result of global warming, however, tourism and the entire Alpine economy could face serious problems in the future.
"Relatively little systematic research has been carried out on disaster phenomena in tourism, the impacts of such events on the tourism industry, and the responses of industry and relevant government agencies to cope with these impacts." (Bill Faulkner, 2 оо I, in: Towards a framework for tourism disaster management, Tourism Management 2 2, $p$ I 36)

\section{Introduction}

The European Alps are affected by natural disasters (avalanches, landslides, mud flows, floods, forest fires) to an exceptional degree. At the same time, these mountains are particularly attractive for tourists. It is assumed that climate change and global warming could cause an increase in the number of natural disasters in the future, resulting in a growing threat to Alpine tourism. Considering this, it is surprising how little systematic research has been carried out on the effects of natural hazards on Alpine tourism.

In the case of Switzerland, nothing at all was published on these subjects prior to 1999 . Subsequently, triggered by the "avalanche winter of 1999," a comprehensive survey on the effects of natural haz-

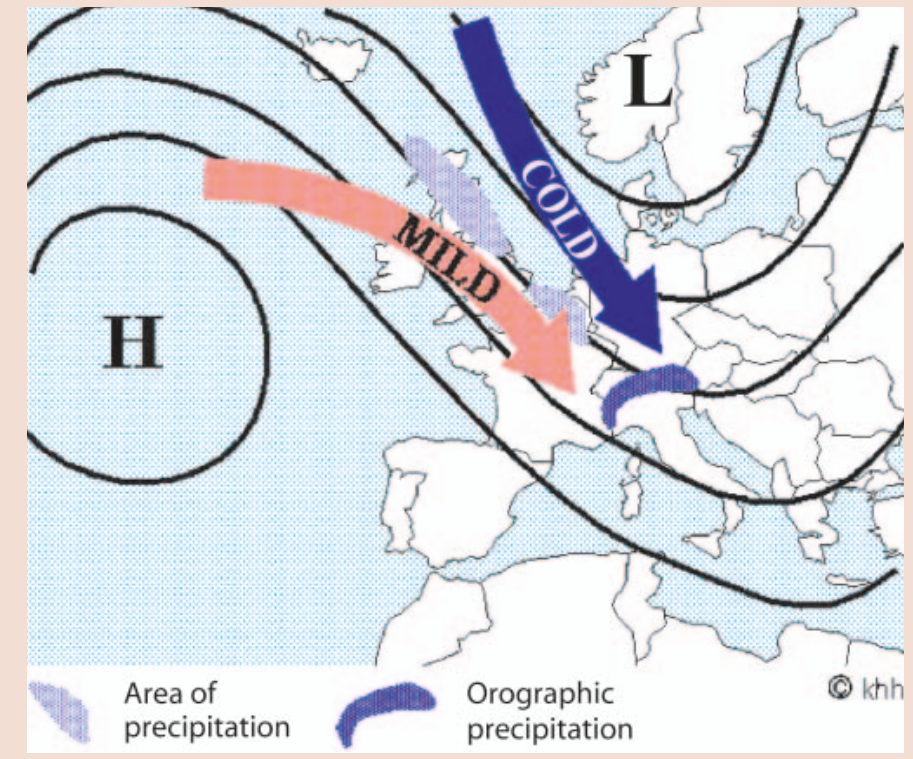

FIGURE 1 Three periods of stormy northwesterly winds caused the avalanche winter of 1999. (Source: SMA MeteoSchweiz) ards on tourism in the Alps was carried out by Nöthiger (2003) at the Swiss Federal Institute for Snow and Avalanche Research (SLF) in Davos. Some of the results of this survey are presented here.

\section{The avalanche winter of 1999}

The "avalanche winter of 1999" refers to the month between 27 January and 25 February 1999. Three precipitation periods accompanied by stormy northwesterly winds occurred in this period (Figure 1). Within 30 days, $5 \mathrm{~m}$ of new snow accumulated on the northern flank of the Alps, ie more than the usual amount for the whole winter. Approximately 1000 destructive avalanches occurred in Switzerland alone. Throughout the Alps, 71 people were killed by avalanches in inhabited areas or on roads: 12 in France, 17 in Switzerland and 41 in Austria (Figure 2). In addition, another 74 winter sport tourists were killed by avalanches during the winter of 1998-1999 in the Alps.

\section{Direct and indirect effects}

The negative effects of natural disasters can be divided into direct and indirect damage. Direct damage refers to the costs generated by the direct impact of the event on buildings, infrastructure, forests and farmland. Indirect effects result from changed conditions brought about by a natural disaster. They may consist of loss of earnings due to direct damage, evacuations, or the closure of access roads. The costs of direct damage correlate to a great degree with the costs of reconstruction work. Hence businesses entrusted with the job of reconstruction, such as the building trade, can eventually profit from these costs. Along with this "direct benefit," natural disasters can also have "indirect bene- 


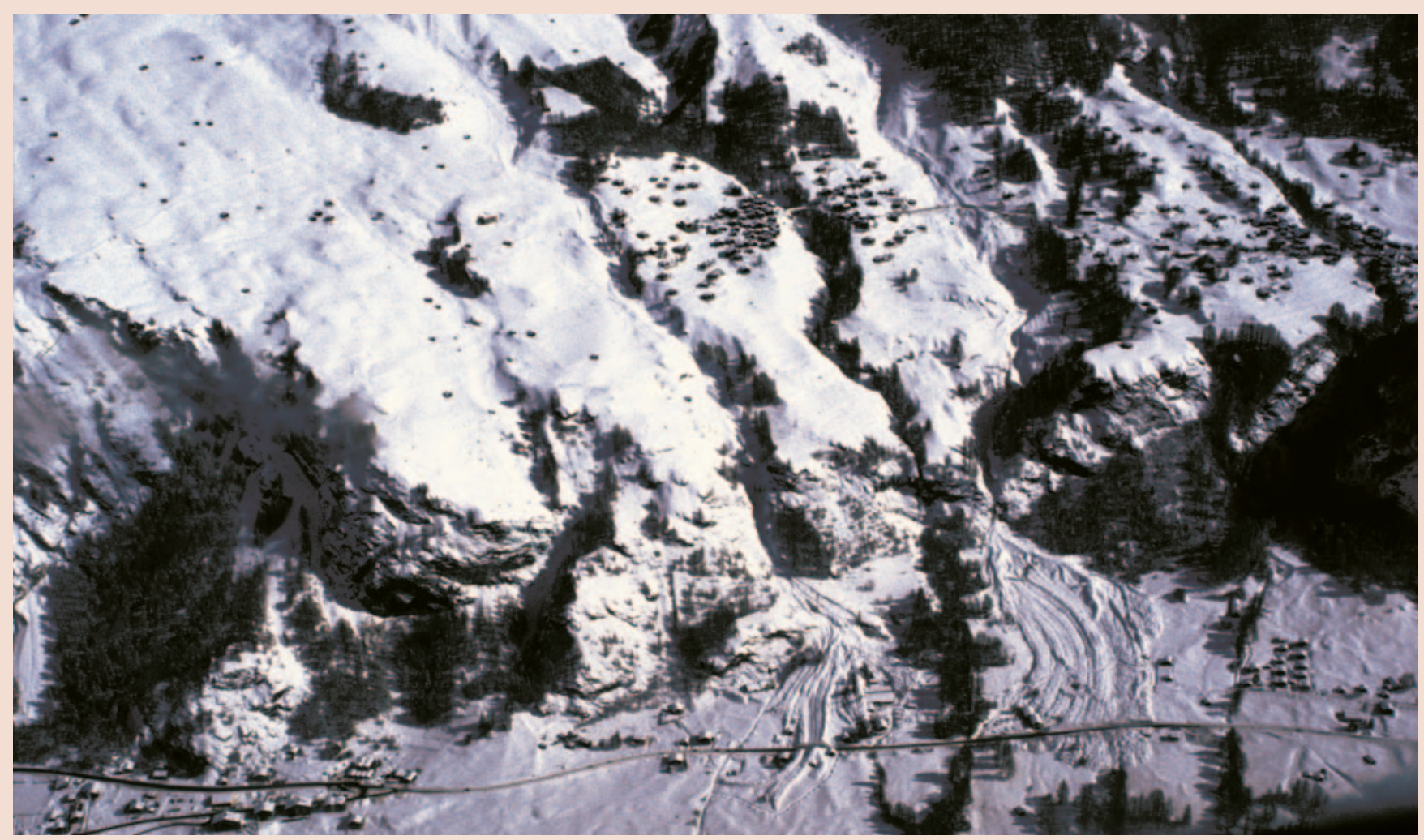

fits," such as "sensationalist tourism" or the transfer of tourists to areas not affected by disaster. However, it is highly unlikely that these benefits can even come close to compensating for the indirect costs. Aside from their financial effects, natural disasters also have other effects that are beyond the scope of this article. The following explanations focus on the direct and indirect costs of the avalanche winter of 1999 for Swiss tourism.

In Switzerland, the direct costs of the avalanche winter totaled US\$ 313 million (Table 1). Approximately US\$ 21 million, or $7 \%$ of this total, are related to damage to tourist infrastructure, with cable cars and ski lifts being the most affected (Figure 3). Considering the great importance of the tourist industry to the alpine economy, these costs must be characterized as minor. Agriculture, for example, was affected by direct costs to a far greater extent in comparison.

Indirect costs present an entirely different situation. Tourism was clearly the most affected branch in terms of indirect costs. Indirect costs to tourism can have several causes: their occurrence is probably most obvious if a building has been damaged to such an extent that working inside it is no longer possible. In this case, indirect costs would be equivalent to the earnings that cannot be realized during reinstatement. However, it is assumed that the closure of access roads in conjunction with a natural disaster has a greater economic impact. For example, in February 1999 more than 40 tourist resorts in Switzerland were cut off from the outside world for up to 14 consecutive days, resulting in indirect costs due to the complete absence of day trippers. Where roads remained closed for a particularly long time, overnight guests had to be air-lifted (Figure 4), leading to even greater losses.

The decommissioning of cable cars and ski lifts represents another potential

\begin{tabular}{|l|r|}
\hline Damage category & $\begin{array}{c}\text { Costs } \\
\text { (in million Us\$) }\end{array}$ \\
\hline Buildings & 139 \\
\hline Personal property & 41 \\
\hline Streets & 45 \\
\hline Railway lines & 8 \\
\hline Cable cars / ski lifts & 12 \\
\hline Protective structures & 6 \\
\hline Power supply system & 19 \\
\hline Forests & 33 \\
\hline Farmland & 10 \\
\hline Total & $\mathbf{3 1 3}$ \\
\hline
\end{tabular}

FIGURE 2 Evolene (Canton of Valais, Switzerland): the runout zones of the massive avalanche of 21 February 1999, which killed 12 people. (Photo courtesy of SLF)

TABLE 1 Direct costs of the avalanche winter of 1999 in Switzerland. (Source: SLF 2000) 


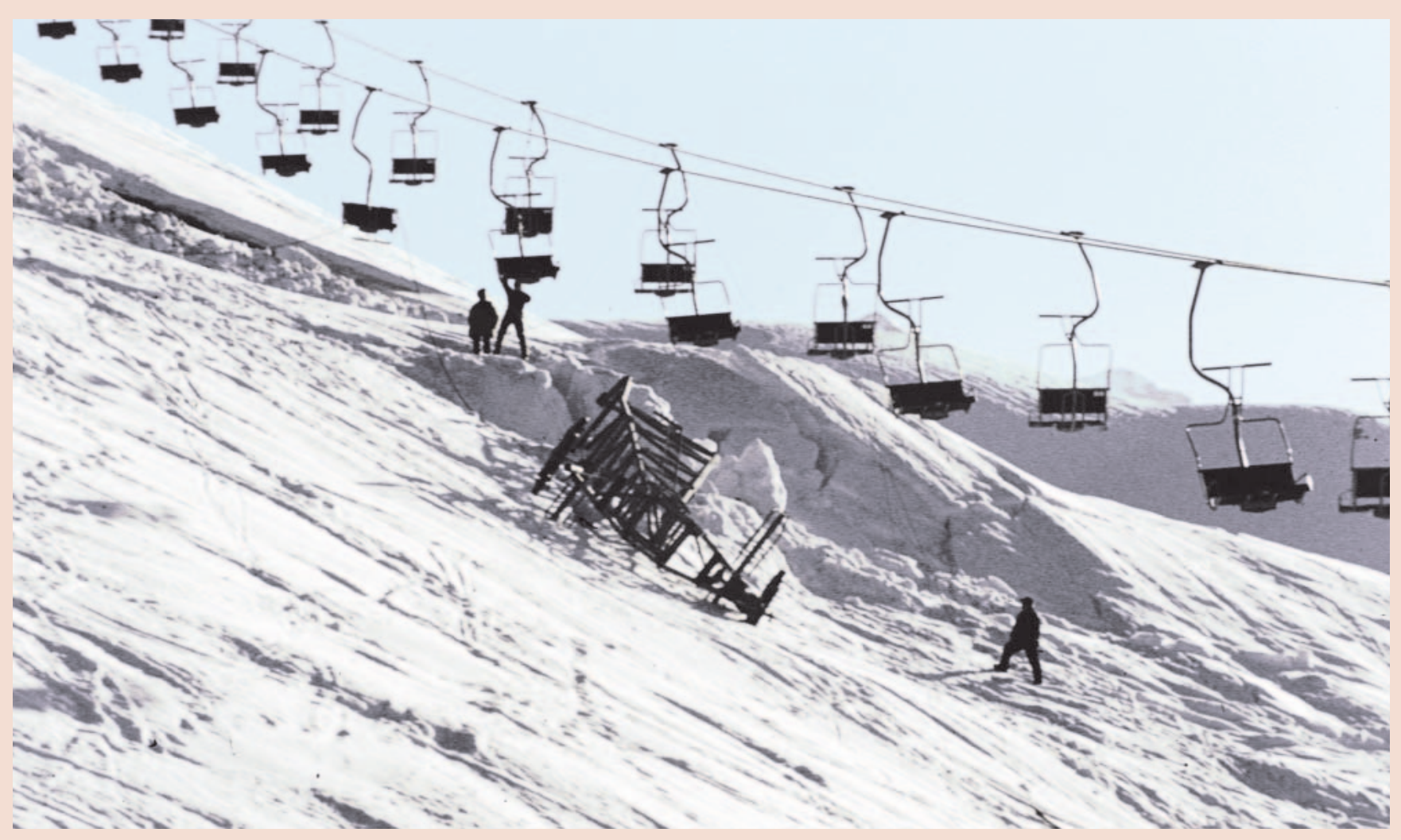

FIGURE 3 Chair lift pylon damaged by snow pressure on 14 March 1999, in Hasliberg (Canton of Berne, Switzerland). (Photo courtesy of SLF)

"Swiss ski resorts see heavy snowfalls but light revenues." (Headline in the Financial Times 23.2.1999) loss to the tourist industry: in February $1999,45 \%$ of the Swiss cable cars and ski lifts were out of operation for 7 days on average. This meant that most day trippers still stayed away, although access roads were actually open. Not only cable car companies but the rest of the tourist industry as well had to bear the financial costs of this situation.

\section{Indirect effects take longer to subside}

Whereas direct damage is closely linked to the very moment a natural disaster occurs, indirect effects can be felt over subsequent weeks and months as well. It can be expected, however, that the number of day trippers will recover after a relatively short period of time, even if it decreases dramatically immediately after the event. On the other hand, the number of overnight stays will not hit its low point until at least a month after the event, owing to the delayed impact of cancellations. Moreover, the number of overnight stays takes longer to recover than the number of day trippers. The impact of a natural disaster on overnight stays may still be felt for as long as a year after the event, while it no longer seems to be a matter of concern to day trippers at this point. If a disaster does not cause a substantial number of casualties on traffic routes and within residential areas, no negative effects on tourism are to be expected to last longer than one year after the event.
Using a newly developed procedure, it was possible to make a rough calculation of the loss of earnings to the Swiss tourist industry caused by the avalanche winter of 1999. Among other things, this procedure is based on extensive surveys of tourists and business owners in tourist resorts, as well as most large cable car and ski lift companies in Switzerland. The loss of earnings computed for the tourist industry in the Swiss Alps was US\$ 215 million (Table 2). This means that the indirect costs of the avalanche winter of 1999 to the tourism sector were 10 times higher than the direct costs. This is presumably a typical feature of the effects of natural hazards on tourism.

TABLE 2 Loss of earnings in the Swiss Alpine tourist industry caused by the avalanche winter of 1999. (Source: Nöthiger 2003)

\begin{tabular}{|l|c|}
\hline Earnings category & $\begin{array}{c}\text { Losses } \\
\text { (in million Us\$) }\end{array}$ \\
\hline Lodging & 30 \\
\hline Catering & 78 \\
\hline Retail & 32 \\
\hline Cable cars / Ski lifts & 59 \\
\hline Other & 16 \\
\hline Total & $\mathbf{2 1 5}$ \\
\hline
\end{tabular}




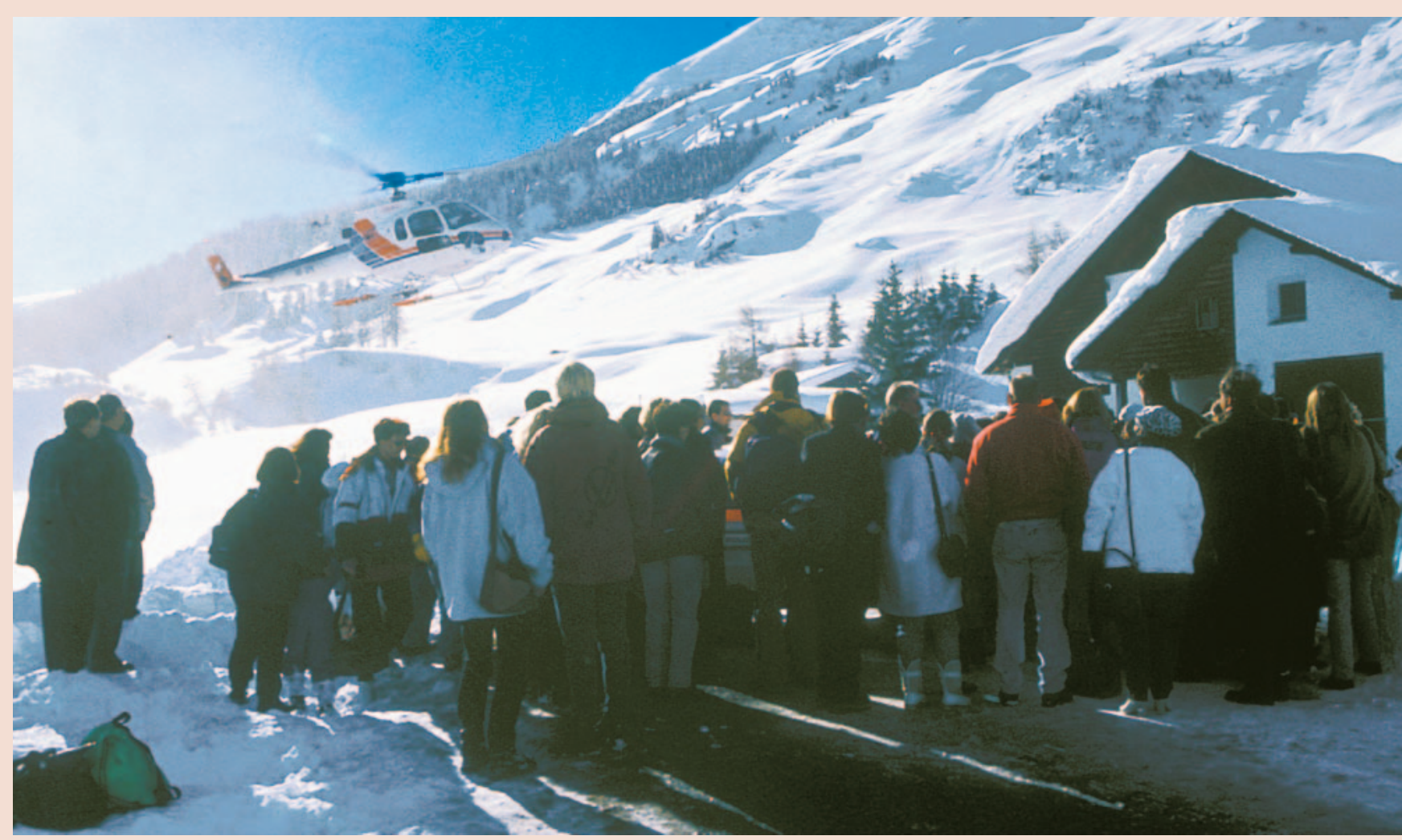

In conjunction with indirect loss, the biggest problems relate to reimbursement issues. Direct costs will usually be covered by insurance companies and public authorities. The companies and people affected are left with only comparably small sums to pay themselves. The opposite is the case with indirect costs. A case study on the avalanche winter of 1999 showed that over $90 \%$ of indirect costs had to be borne by the companies and people affected, as such costs are generally considered a personal risk, the tourist branch being no exception.

\section{Measures for coping with indirect costs}

Since these conditions are unlikely to change in future, the tourist industry should focus on improvements in the field of communication to reduce the indirect costs of future disasters. In this context, professionalizing public relations during a crisis is probably the most beneficial meas- ure. One of the greatest problems faced by people in charge of public relations in the event of a natural disaster is how to maintain media interest in a tourist resort beyond the point where the general situation has "returned to normal."

It would also be desirable to make the broader public more aware of the indirect costs of natural disasters. For example, when planning new protective structures against natural hazards, it is necessary to take into account more than the direct damage such structures could prevent. It is equally important to point out the indirect costs of hazards to the tourist industry and the economy in general, which could be prevented by the protective measures in question. This is particularly important, as measures that can prevent a natural disaster or reduce its direct impact are at the same time the most efficient means of preventing indirect costs.

\section{ACKNOWLEDGMENTS}

This article is based on the PhD thesis of Christian Nöthiger, which was completed at the Swiss Federal Institute for Snow and Avalanche Research (SLF) in Davos, Switzerland.

\section{AUTHORS}

\section{Christian Nöthiger}

Ruetschistrasse 27, 8037 Zurich, Switzerland. ch.noethiger@gmx.ch

Christian Nöthiger has carried out research on the effects of natural hazards on tourism in the Alps over the

past 4 years whilst working at the Swiss Federal Institute for Snow and Avalanche Research in Davos. Currently he is teaching geography at high-school level in Zurich and Wetzikon.

\section{Hans Elsasser}

Institute of Geography, University of Zurich,

Winterthurerstrasse 190, 8057 Zurich, Switzerland. elsasser@geo.unizh.ch

Hans Elsasser is professor of geography at the University of Zurich and head of the Economic Geography Division. His main interests are in the field of economic geography, regional development, spatial planning, tourism and Alpine studies.
FIGURE 4 Tourists in Davos (Canton of Grisons, Switzerland) awaiting evacuation by air. (Photo courtesy of SLF)

\section{FURTHER READING}

Nöthiger C. 2003. Naturgefahren und Tourismus in den Alpen. Untersucht am Lawinenwinter 1999 in der Schweiz [PhD dissertation]. Davos, Switzerland: Swiss Federal Institute for Snow and Avalanche Research.

Nöthiger C, Bründl M, Ammann W. 2001. Die Auswirkungen der Naturereignisse 1999 auf die Bergbahn- und Skiliftunternehmen der Schweiz. Tourist Review 56(1):23-32. Nöthiger C, Elsasser $\boldsymbol{H}$, Bründl $\boldsymbol{M}$. 2002. Indirekte Auswirkungen von Naturgefahren auf den Tourismus. Das Beispiel des Lawinenwinters 1999 in der Schweiz. Geographica Helvetica 57(2):91-108.

OcCC [Organe consultatif sur les changements climatiques]. 2003.

Extremereignisse und Klimaänderung. Berne, Switzerland: OcCC.

SLF [Swiss Federal Institute for Snow and Avalanche Research]. 2000. Der Lawinenwinter 1999. Davos, Switzerland: Swiss Federal Institute for Snow and Avalanche Research. 